\title{
Nurturing business ecosystems for growth in a foreign market: Incubating, identifying and integrating stakeholders
}

\author{
Ke Rong ${ }^{\mathrm{a}, \mathrm{b}}$, Jinxi $\mathrm{Wu}^{\mathrm{c}, *}$, Yongjiang Shi ${ }^{\mathrm{d}}$, Liang Guo ${ }^{\mathrm{e}}$ \\ a Business school, Bournemouth University, Bournemouth, BH8 8EB, UK \\ ${ }^{\mathrm{b}}$ Harvard Business School, Soldiers Field, Boston, MA 02163, USA \\ c School of Social Science, Tsinghua University, Beijing 10084, China \\ d Institute for Manufacturing, University of Cambridge, Cambridge CB3 OFS, UK \\ e NEOMA Business School, 1 rue du Maréchal Juin - BP 215, 76825 Mont-Saint-Aignan Cedex, France
}

\section{A R T I C L E I N F O}

\section{Article history:}

Received 19 November 2013

Received in revised form 22 April 2015

Accepted 27 July 2015

Available online $\mathrm{xxxx}$

\section{Keywords:}

Business ecosystem

Internationalization

Network approach

Demand

Road map

Stakeholders

\begin{abstract}
A B S T R A C T
This paper explores the process of nurturing a business ecosystem to facilitate corporate growth in an unfamiliar foreign market with high product uncertainty and no network resources. The authors conducted a qualitative, longitudinal study by examining a successful business case ARM (a leader in microprocessor intellectual property) - to demonstrate how firms nurture their business ecosystems to develop in the Chinese market and to stimulate demand even without the advantages of resources and stabilized products. Based on the road map method, this paper develops a framework of creating a business ecosystem in three sequential stages namely, incubating complementary partners, identifying leader partners, and integrating ecosystem partners. The findings enrich classic international business and demand chain theories by highlighting different roles stakeholders adopt to cope with uncertain products in a foreign market. In practical terms, these findings also provide Mode 2 knowledge with application context (Gibbons et al., 1997) on entering new markets by building up an ecosystem.
\end{abstract}

(c) 2015 Elsevier Inc. All rights reserved.

\section{Introduction}

In the classic international business context, multinational enterprises (MNEs) experience unfamiliarity during internationalization, since they have to introduce their products to the market in new, highly uncertain business environments (Bell, 1995; Chen, 2003; Contractor, 2007; Dunning, 1988; Ji and Dimitratos, 2013; Johanson and Vahlne, 1977; Johanson and Wiedersheim-Paul, 1975). MNEs usually expand into international markets using their original network resources in order to gradually develop their profiles (Johanson and Wiedersheim-Paul, 1975; Chen, 2003). Through this gradual process, an MNE is able to accumulate capabilities, experience, and network resources (Geringer, 1991; Keeble et al., 1998) that help it cope with liabilities of foreignness and alienation (Zaheer, 1995; Vahlne et al., 2012; Denk et al., 2012).

However, new international business contexts can arise if a potential market has a more complex environment on the demand side (Adner, 2012; Doz et al., 2004; Priem et al., 2012). Such a phenomenon is termed product uncertainty, which has three types of implications. First, product uncertainty creates a lack of dominant design for products in the emerging industries. Second, it brings out an uncertain demand for products. And third, the supply network system is not ready to produce such potential products. All the stakeholders in such a new international business context have to deal with the uncertainties of product design, demand, and working partners. In addition, the situation could be even more complicated for a focal firm owning a technological platform

\footnotetext{
* Corresponding author.

E-mail addresses: zryears@gmail.com (K. Rong),wujx02@mail.tsinghua.edu.cn (J.Wu), ys@eng.cam.ac.uk (Y. Shi), liang.guo@neoma-bs.fr (L. Guo).
} 
(Thomas et al., 2015): it needs to encourage international partners to add value to the platform and create end user products. In such circumstances, internationalizing firms need to act more proactively to create local demand and connect with local partners to finalize the products.

Classic international business (IB) and operations management (OM) theories in an international context have rarely addressed these emerging and ongoing issues. First, classic IB theories such as the stage and network approach models use a resourcedominated logic (Johanson and Vahlne, 1977; Chen and Chen, 1998; Dunning, 2001; Ji and Dimitratos, 2013; Musteen et al., 2014) to determine whether firms should internationalize or not; these models appear to have a passive attitude toward internationalization. Internationalization occurs only because the firm possesses resource advantages and the demand already exists in other overseas markets. The firm, therefore, extends its technology or service to these less developed international markets. However, these theories fail to address the proactive creation of demand or the appropriation of value from the process of demand creation. Second, classic IB and OM theories are used mainly in mature industries. The recent internationalization of technological providers in emerging industries with uncertain products (Rong et al., 2013c) has generated a greater challenge - in not only creating demand for the products, but also initiating the products themselves based on those platforms. Such firms have to stimulate new partners to realize a dominant product design, nurture the business environment to increase product demand (Rong et al., 2013c), and manage internationalization.

Recently, industrial players who are technological platform providers have started using the concept of the "business ecosystem" (Garnsey et al., 2008) to deal with new challenges and uncertainties by addressing the demand side. A business ecosystem is an independent economic community with different stakeholders, including direct industrial players, government agencies, industry associations, competitors, and customers, who mutually benefit each other and face similar outcomes (Iansiti and Levien, 2004; Moore, 1993). The hidden power of a business ecosystem lies in its dynamic mechanism, which makes it possible to transform a passive social network (Burt, 2010; Eisingerich et al., 2010) into an active value creation chain (Shang and Shi, 2013). Thus, the business ecosystem approach might equip firms with a more proactive attitude in overseas markets by exploring the demand side of uncertain products. As a result, a firm will be able to explore the local network thoroughly even if it has no previous advantages (Dunning and Lundan, 2008; Rong et al., 2011).

This study intends to answer a research question - how firms follow the business ecosystem approach to enter a foreign market and deal with complex, untraditional challenges like product uncertainty. This study explores the story of ARM, a semiconductor intellectual property (IP) supplier in China, whose success is due to its technological platform and business ecosystem. IP is a reusable unit of integrated circuit (IC or chip) design layout that performs some specific function and constitutes the fundamental architecture of chips used in digital products (Kaeslin, 2014). ARM's IPs are licensed to third-party IC design firms to accelerate the design and lower the cost. Because of this, ARM functions as a technological platform provider and positions itself in the upstream of the semiconductor supply chain. ARM started as a small company with only 12 engineers in Cambridge, U.K., in the early 1990s. Today, it is the world's leading semiconductor IP supplier. Its IP architecture firmly dominates the mobile phone microchip market (Burt, 2014). Thanks to its excellent business ecosystem nurturing strategy (ARM Holdings and PLC, 2014), it currently has more than 800 partners in its community.

Although ARM is the market leader in the West, it gains few advantages in China in terms of ownership, location, and internalization. At the time of its entry onto the Chinese market in 2001, there was no existing end user product market for ARM's IP model and no human resources for ARM's technology. The firm had successfully built up a brand new business ecosystem to meet the challenges of unfamiliarity and triggered downstream demand for its IPs. ARM's case in China demonstrates how important it is for an MNE to nurture a business ecosystem so that the firm is able to overcome its disadvantages in a new international market environment.

This study employs the road map approach (Phaal et al., 2011) to identify the key stages of nurturing business ecosystems in a foreign market. The sequential stages of nurturing a business ecosystem include incubating complementary partners, identifying leader partners, and integrating ecosystem partners. During the process, different stakeholders contribute to the mutual growth and achieve a win-win situation. Our study primarily enhances the existing understanding of business ecosystems (Mills et al., 1995; Neely et al., 2000; Behrens, 2012) by focusing on the stages of business ecosystem nurture. It also proposes a proactive strategy that considers a wider range of stakeholders and explores the new international business context of product uncertainty. This proactive internationalization strategy is complementary to those proposed by classic IB theories, such as the stage model (Johanson and WiedersheimPaul, 1975; Johanson and Vahlne, 1977), the network approach to internationalization (Chen, 2003; Wang et al., 2014), and international production networks (Dunning, 1988; Shi and Gregory, 1998; Fisch and Zschoche, 2012). In summary, instead of examining Mode 1 knowledge, as most IB research has, this paper addresses Mode 2 knowledge. Traditional IB theories focused on Mode 1 knowledge (Gibbons et al., 1997; Nowotny et al., 2003; Jiménez, 2008) looked at the taxonomy of an IB discipline or the determinants of a phenomenon. Mode 1 knowledge production is purely academic and mono-disciplinary, and it is focused on scientific discovery, which is characterized by the hegemony of theories, experimental science research output, and an internally driven taxonomy of disciplines. As a result, Mode 1 knowledge is to solve the problem of what and why during internationalization. Mode 1 knowledge is very different from Mode 2 knowledge, which is socially distributed, application oriented, transdisciplinary, and subject to multiple accountabilities. Thus, application-oriented Mode 2 knowledge addresses how to do things during internationalization (Gibbons et al., 1997; Van Aken, 2005; Hessels and Van Lente, 2008), such as the process of how to nurture a phenomenon. This is very different from the traditional IB theories featuring Mode 1 knowledge.

The rest of the paper is structured as follows: Section 2 provides a literature review on international business, international production network, and business ecosystem approaches and then highlights research gaps in the extant literature. The methodology section addresses the data collection and analysis methods used in the case study. Section 4 presents the road map method and the 
case of ARM's internationalization in the Chinese market. The case study identifies the typical stages of nurturing a business ecosystem and develops its theoretical proposals. Then, Section 6 discusses the framework's contributions to business ecosystem, international business, and demand side theories. Finally, the paper concludes and proposes avenues for future research.

\section{Literature review}

\subsection{Classic international business theories}

Current IB theories mainly use resource-dominant logic to address internationalization activities (Johanson and Vahlne, 2009; Moghaddam et al., 2014), indicating that companies are reluctant to penetrate the market without resource advantages and, therefore, proactively create resources. Dunning and his colleagues proposed an eclectic framework of ownership (Hymer, 1976), location (Vernon, 1966), and internalization (Buckley and Casson, 1976) with a more active nature that can be used to evaluate the impact of market, resources, knowledge, efficiency, global value and geopolitics on the success of internationalization strategy (Dunning, 1988, 2000, 2001; Dunning and Lundan, 2008; Moghaddam et al., 2014). These OLI elements (i.e., ownership advantage, location advantage, and internationalization advantage) of the eclectic paradigm have been used widely by managers to identify the nature of a given firm's advantage over rivals in a host market. However, according to the liability of foreignness theory (Zaheer, 1995), an international firm is in a weak position versus competing local firms in host countries; this is due to the international firm's lack of experience, unfamiliarity with the local environment, and lack of network support (Moeller and Harvey, 2011; Gooris and Peeters, 2014). International parent firms also face the liability of outsidership so that they cannot easily make appropriate decisions for their subsidiaries in a host market (Johanson and Vahlne, 2009; Vahlne et al., 2012). These two challenges are especially true for firms that are just starting their international expansions. As a result, it is important to achieve local embeddedness (Keeble et al., 1998; Andersson et al., 2005; Dellestrand, 2011), engaging with the local network and identifying business opportunities to mitigate the liability of outsidership (Vahlne et al., 2012; Schweizer, 2013). Most IB theorists mainly address the determinants of local embeddedness, such as the mechanisms that control the relationship between parent companies and subsidiaries, the structure of the market, the type of industry, and the size, scope, and age of the subsidiary (Uzzi, 1996; Newburry and Yakova, 2006; Collinson and Wang, 2012; Nell and Ambos, 2013). Further expansion of business opportunities is supported through achieving local embeddedness (Andersson et al., 2005).

Following the resource advantage logic, the stage model (Johanson and Wiedersheim-Paul, 1975; Johanson and Vahlne, 1977) suggests that firms should expand their international scopes through different stages, ranging from no regular exports, regular exports, sales subsidiaries to overseas manufacturing plants. This cautious approach helps firms mitigate the risk of internationalization. The stage model takes into account the psychic distance between the home and host countries and assumes that firms gradually increase their commitments to the host market (Yang et al., 2011). Prior studies on the stage model find that an international joint venture can be an efficient internationalization strategy if firms select their foreign partners wisely, using appropriate selection criteria, such as a good fit with the headquarter's success criteria, the activities or decisions they control, and control mechanisms (Geringer, 1991). The stage model, however, fails to explore the process of nurturing an overseas network in collaboration with partners in great detail (Welch and Paavilainen-Mäntymäki, 2014). Also, most stage theorists regard internationalizing firms as focal points in terms of partner networks, and they minimize the effect of context (Bell, 1995; Child and Rodrigues, 2005; Johanson and Vahlne, 1977, 2009). These theorists mainly use the stage model at the level of firm behavior in IB theories. Thus, they do not identify the corresponding transformations in the business network that can facilitate and sustain internationalization.

The network-based approach (Chen, 2003) has the potential to identify these transformations and has gained attention in the recent internationalization process literature (Blomstermo et al., 2004; Chen, 2003; Chetty and Blankenburg Holm, 2000; Hilmersson and Jansson, 2012; Musteen et al., 2014). The network approach takes a broader view of linkages. All firms in a market - including designers, suppliers, subcontractors, customers, and other partners - are considered to be embedded in one or more networks (Chen and Chen, 1998; Chen, 2003; Lee et al., 2014). Foreign direct investment (FDI) can act as a stimulant, linking the domestic network to a potential foreign network and enabling the company to internationalize while avoiding the problem of network distance (Johanson and Mattsson, 1988; Chen, 2003). Scholars have observed that internationalization through FDI normally begins in places that are close to the domestic market and have access to its resources. Once the company has accumulated enough network resources, it moves to a more distant location (Chen and Chen, 1998; Chen, 2003; Ciravegna et al., 2014). Often, companies prefer locations with good human skills, financial resources, market opportunities, technological capabilities, etc. (Blomstermo et al., 2004; Chen, 2003).

The network approach literature emphasized the accumulative approach, in which a firm expands its network resources by accumulating experience and capability before linking up with local networks to secure advantages (Chen, 2003; Chen et al., 2004; Chetty and Blankenburg Holm, 2000). However, the network approach is still at an early stage in tackling international business networks. That is because, on the one hand, it focuses on the determinants of network expansion, but not on the process of developing a network during internationalization and the way in which a network configuration matches and then facilitates internationalization strategies (Shi and Gregory, 1998; Li et al., 2000; Shi and Gregory, 2005; Ge and Wang, 2013). On the other hand, the network approach cannot explain why many companies enter international markets even without network resources (Rong et al., 2015). An example of this is the bandwagon effect (Bandura, 2001; Secchi, 2009) - companies have to enter the same markets as their numerous competitors or the markets in which competition is likely to take place in the near future. This leads firms to nurture their network resources in nascent locations instead of expanding gradually (Adner, 2012). Finally, the network approach does not address network configuration in general (Ferdows, 1997; Shi and Gregory, 1998; Hilmersson, and Jansson, 2012) and network development in the scenarios posing demand uncertainty in particular (Adner, 2012). Therefore, there is a need to investigate the way companies establish their 
business networks and stimulate the local community in a host country to achieve multinational expansion and secure competitive advantage (Gulati et al., 2012; Immelt et al., 2009). It is important for IB theorists to learn from the international production and global supply network studies, which explore international network configuration at great length (Pananond, 2013; Schmeisser, 2013) and the gradual network development process (Lambert and Cooper, 2000; Shi and Gregory, 1998; Srai and Gregory, 2008; Liu et al., 2014).

\subsection{International production network, global supply, and demand chain}

International production network (IPN) theories were developed from classic operations management when multinational firms began to internationalize their manufacturing networks (Ferdows, 1997; Shi and Gregory, 1998) and manage the evolution of different roles in those networks (Ferdows, 1997; Pananond, 2013). Global supply chain/network (GSN) theories, one recent branch of IPN theories, address how multinational firms outsource noncore activities to their partners in the domestic and overseas markets (Lambert and Cooper, 2000; Srai and Gregory, 2008; Zhang and Gregory, 2011).

IB theories derived from economics focus on FDI, the determinants of internationalization, and the lack of network development, so they are often criticized by IPN and GSN studies (Shi and Gregory, 1998; Adner, 2012). Prior studies argue that both IPN and GSN theories shed light on production network configuration, manufacturing internalization processes, and reconfiguring the network for internationalization (Ghoshal and Bartlett, 1990; Shi and Gregory, 1998; Zhang and Gregory, 2011; Pananond, 2013). Ferdows (1997) represents the international manufacturing system as a network of factories with the primary strategic goal of gaining low-cost production, skills/knowledge, and proximity to markets. Shi and Gregory (1998) propose the international manufacturing networks (IMN) approach that refers to multi-nationally dispersed factory systems for a product family or a strategic business unit. The structural factors of an IMN system are determinants of various system configurations, while infrastructural factors are dynamic controllers, ranging from daily operations and accumulative improvement to product transfer and network evolution during internationalization (Shi and Gregory, 1998).

Some scholars examine the demand side of the supply chain (Korhonen et al., 1998; Williams et al., 2002; De Treville et al., 2004; Priem and Swink, 2014; Validi et al., 2014) to explore the strategies to increase value from the whole international supply chain network. Demand chain management focuses on market power as a key to better management of the former supply chain, to achieve quick response and agility (Hilletofth, 2011) in four ways: from product focus toward customer focus, from functional to process organization, from inventory to information, and from forecast driven to demand driven (Jüttner et al., 2007; Christopher, 2010). By shifting those four aspects and by focusing on the market and customer requirements, a firm can transform efficiency-driven supply chain management into effectiveness-driven demand chain management (Rainbird, 2004).

However, the theories of IPN, GSN, and the demand chain management assume that end user products are finalized and mature (Parente et al., 2011; van Veen-Dirks and Verdaasdonk, 2009; Jüttner et al., 2007). These theories overemphasize the importance of quickly setting up a production network and delivering the final product in a short time in order to achieve rapid market response (Rong et al., 2013b, 2013c). Therefore, these theories are more suitable to a matured internationalization context than to an emerging market full of product uncertainties (for example, in the electric vehicle industry and the mobile computing industry in China, see Rong et al., 2013a, 2013c). A highly uncertain business environment damages the efficiency of international production networks and supply chain management. Different stakeholders, such as policy makers, industrial associations, industrial players, and even customers, should work together to meet uncertain requirements and to initiate products. These stakeholders make up a business ecosystem around emerging industries (Kenney and Pon, 2011; Rong et al., 2013c; Lu et al., 2014). As a result, we need business ecosystem theories to understand how demand side facilitates internationalization and to further extend the scope of the demand chain management theories.

\subsection{Business ecosystem and internationalization}

Factoring all stakeholders into business ecosystems (Wareham et al., 2014; Rong et al., 2015) represents a challenging but promising avenue of research inquiry. Nurturing a business ecosystem helps a focal firm deal with a more complicated institutional environment (Rong et al, 2015). As a focal firm needs not only to develop linkages with its potential direct partners, but also to create an entire ecosystem involving indirect partners, a healthy business ecosystem helps the internationalizing firm develop a dominant product design and stabilize evolving business circumstances (Adner and Kapoor, 2010; Rong et al., 2013a).

Within a business ecosystem, focal firms or keystone firms refer to those that provide platforms on which the ecosystem can cocreate value (Adner and Kapoor, 2010; Iansiti and Levien, 2004). Complementary or niche players are included in the focal firm's commercialization process, adding value to the entire ecosystem (Adner and Kapoor, 2010; Cusumano, 2011). Given that these niche players become part of the business ecosystem, the concept of business ecosystem is much broader than that of the classic direct business system view, offering all stakeholders the possibility of coevolving with the focal firm. The focal firm acts as an incubator and is not just exploiting a host country. In addition, building its own ecosystem with complementary players around its products or services helps the focal firm accumulate resources directly in the local market and mitigate risk.

However, there is a paucity of existing literature that examines the business ecosystem development process (Rong et al., 2015). Although Moore $(1993,1996)$ proposes the business ecosystem life cycle model, which includes the four stages of birth, expansion, authority, and renewal, his theory does not incorporate the behavior of different roles within the life cycle stages, and his empirical studies cover only established - not emerging - industries (Rong et al., 2013b). A few recent studies in the field address the uncertainty within a business ecosystem and corresponding strategies (e.g., Kapoor and Lee, 2013; Chesbrough et al., 2014; Mäkinen et al., 
2014), but the dimension of international market uncertainly is still missing (Behrens, 2012). Therefore, as most previous IB literature focuses on the pre-entry decision to internationalize, the process of establishing a brand new, post-entry business ecosystem in a foreign market needs further exploration. It is especially important to examine how focal firms proactively nurture their business ecosystem partners and gain competitive advantages via coevolution.

\subsection{Summary}

Our literature review reveals that classic international business theories mainly focus on the OLI elements of the eclectic paradigm, while the network approach focuses on the reasons for internationalization but not on the nature of international network. Both IPN and GSN theories emphasize operation efficiency but pay little attention to the demand side. Although the business ecosystem theory provides a broader perspective than IPN and GSN theories, few scholars have tried to understand how an internationalizing firm establishes its business ecosystem and achieves competitive advantage with its foreign partners. This study intends to fill this research gap by conducting a successful internationalization case study of ARM in China.

\section{Method}

\subsection{Research setting}

This study adopted the longitudinal case study approach (Yin, 2008) to address the research question by applying the processoriented road map method (Mills et al., 1995; Neely et al., 2000; Phaal et al., 2011). This paper explores the case of ARM in order to understand how a nurtured business ecosystem confers a competitive advantage in China. As an IP provider, ARM is positioned upstream in the value chain, as shown in Fig. 1, and is far from the demand side and end users in the mobile computing industry. ARM's business ecosystem is composed of three parts (Moore, 1993): core business, extended supply chain, and other ecosystem partners. The company's core business is to offer ARM IP to its customers and to stimulate downstream demand. The extended supply chain includes design support and application-related partnerships with, for example, operating system vendors (OSV), independent software vendors (ISV), or content providers to facilitate ARM's supply chain. The other stakeholders can be regarded as ecosystem partners who indirectly contribute to the supply chain. For example, an ARM technology textbook published by a university can make Chinese IC engineers familiar with ARM's IP. Consortia are also important ecosystem partners who organize events and exhibitions to promote ARM's technologies. Both direct and indirect partners eventually create a business ecosystem around ARM IP.

ARM's IP license-based business model faces four major challenges. The first challenge is to convince IC design firms to adopt its IP architecture, instead of the IP architecture of other microchip giants (e.g., Intel, AMD, and Nvidia). The second challenge is to work tightly with IC design firms to optimize the capability and performance of ARM IP by fully customizing their software to

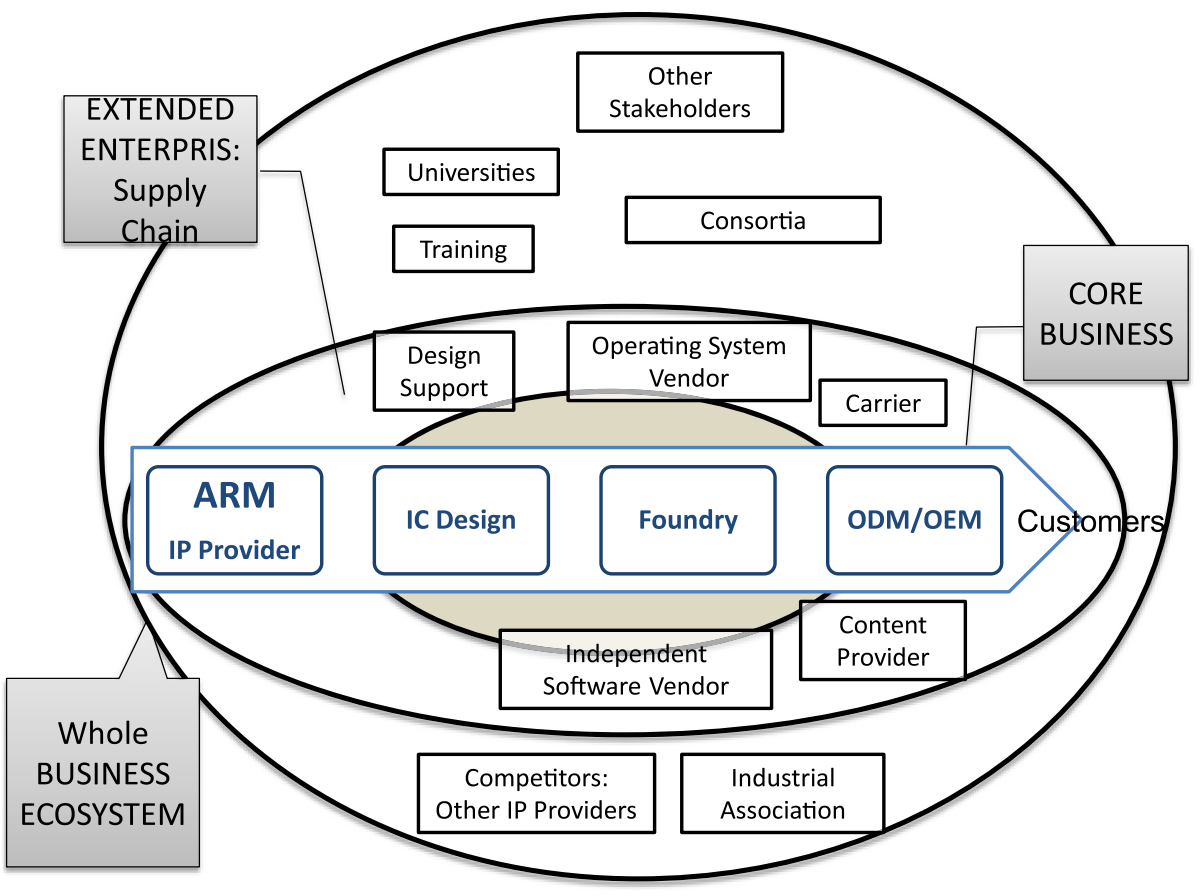

Fig. 1. ARM ecosystem map. 
ARM's architecture and by improving end users' experiences. The third challenge is to reduce lead time and enable foundry players to easily manufacture ARM IP-based microchips. To do so, ARM must share its core IP libraries with IC design tool suppliers and foundry players. And the fourth challenge is to provide endless support to the innovation projects of ARM's downstream partners, as the end user products (i.e., smartphones and other hand-held devices) come out one after the other.

When ARM decided to enter China in 2001, these challenges became even more significant. ARM virtually had no OLI advantages and, even worse, no demand from the local market. Although ARM had already achieved limited success in the West, ARM IP and the accompanying IC design industry were new to Chinese customers. There was no licenser in China who had used ARM IP, and very few Chinese engineers were able to design ARM architecture-based ICs. So, ARM had to provide training to local partners long before it could directly license its IP in China. There was no existing end user solution to adopt ARM's IP in China, discouraging penitential partners from collaborating with ARM. The uncertain environment forced ARM to set up its own business ecosystem in order to provide direct and indirect partners with adequate support, including engineer training programs, design tools, software, and manufacturing systems to facilitate the adoption and incorporation of its IP.

\subsection{Data collection and analysis}

To investigate the process of nurturing a business ecosystem, this study adopted the grounded theory method (Eisenhardt, 1989; Yin, 2008). We did this because of the paucity of prior studies addressing the nurturing business ecosystem process in general (Moore, 1993, 1996; Rong et al., 2013b) and due to the emerging, unestablished nature of IC products.

We first applied the road map method (Phaal et al., 2004; Phaal and Muller, 2009) to identify the key events, which reflect significant ARM strategy changes or important achievements. Then, we mapped out the key dimensions - different types of partners, such as the focal firm (ARM), complementors, and other supporting roles. Next, we followed the road map dimensions to see how to achieve market pull by sharing the focal firm's vision (Reid and De Brentani, 2010) and how to achieve technology push with partners. In particular, we used vision, partner types, and activities as the codes for further analysis of sequential business behaviors. And we finalized the key phases and key activities in terms of vision and partners. In short, the road map method enabled us to examine key events of ARM in great detail and then to outline the typical nurturing process of a business ecosystem as Mode 2 knowledge in the context of application (Hessels and Van Lente, 2008; Jiménez, 2008) with the nature of process studies (Mills et al., 1995; Neely et al., 2000).

Grounded theory and the road map method required us to interview different individuals not only within the focal firm (ARM), but also in its ecosystem partner companies. We identified partner companies using two criteria: they had to be either direct business partners involved in the key events of ARM or important but indirect partners supporting ARM's commercialization. We identified the best persons to interview for optimal data collection. Our interviewees included the CEO of ARM's subsidiary in China (hereafter, ARM China), several directors and project managers of ARM China, project directors in an IC design firm, several associates at OEM firms, and Chinese government employees. We carried out 45 interviews in total, covering 22 companies and spanning 112 h (see the Appendix A). To ensure data triangulation (Saunders et al., 2009) and constructive validity (Gibbert et al., 2008), we also compared the first-hand data with media reports and documentaries on the activities of ARM and its partners in China.

Table 1

List of interview questions.

\section{What is your company's background information? \\ Will you please introduce your company's background? \\ Will you introduce the product portfolio? \\ Who are your partners, suppliers, and customers?}

\section{What is a business ecosystem?}

What is the strategy for nurturing your ecosystem?

How do you nurture ideas to encourage your ecosystem partners?

Can you give a list of partners for each product?

How do you control the project with your partners?

How do you renew your ecosystem?

What are other essential elements of the business ecosystem of your company?

How to nurture a business ecosystem. (Interview at ARM)

Could you please introduce your new product development process? For example, could you briefly introduce the activities, such as R\&D, manufacturing, marketing, and service?

What is the process of promoting such a product?

What other methods are used to nurture the business ecosystem, such as investment in your partners?

How do you work with ARM during its nurturing process? (Interview with ARM's ecosystem partners)

Could you please introduce the development of your products based on or relevant to ARM's IPs; for example, in terms of R\&D, manufacturing, marketing, or service?

How do you promote your products with ARM?

What other methods are used to nurture the business ecosystem?

How do you benefit from the collaboration with ARM?
Interviewee

Director/CEO

Director/CEO

Director/CEO

Director/project manager Director/project manager Director/project manager Director/project manager Director/project manager Director/project manager

Project manager

Project manager

Project manager

Project manager/director

Project manager/director Project manager/director Project manager/director 


\subsection{Interview questions}

The questions we used in our interviews are listed in Table 1. The first set of questions is related to the driving force behind the study of business ecosystems and company background. The second set of questions addresses the map of a business ecosystem from the focal firm's perspective. The third set of questions concerns how the focal firm nurtures its business ecosystem. And the fourth set of questions is for partners in order to discover how they contribute to ARM's business ecosystem nurturing process and how they benefit from the business ecosystem.

\section{Case study}

\subsection{Stage 1: 2001-2003}

In 2001, ARM entered the Chinese market, a small market that accounted for a small proportion of ARM's total revenue. As a result, ARM China was not a key part of ARM's original global strategy; its focus was rather the American and Japanese markets. However, after 12 years of business ecosystem building in Greater China, the Chinese market became the most important one for ARM and accounted for 26\% of its total revenue in 2013 (ARM Holdings and PLC, 2014).

The CEO of ARM China was candid in revealing the obstacles to ARM's entry in China. He said, "We have experienced bigger issues than anticipated. There were some key difficulties. No local company knew ARM and no local engineers had worked on ARM IP. The business in China was totally different from ARM's business venture in the West, where many experienced engineers knew about microchip design." Therefore, ARM's first step in the internationalization process was introducing ARM IP to local businesses and improving the awareness of ARM's technology, not finding licensing partners in China.

From its previous experiences in the West, ARM understood the importance of ecosystem partners, even though those were not directly linked to ARM licensing business (Garnsey et al., 2008) because indirect ecosystem partners encouraged key/direct business partners to adopt ARM IP by facilitating commercialization of key partners' microchips. ARM China enforced two strategies to nurture partners at the first stage of business ecosystem development (see Fig. 2), as noted by the CEO of ARM China,

"Firstly, we set up ARM China training programs for large original equipment manufacturers (OEM) that would use ARM IPbased chips, such as Huawei, ZTE, and many other Chinese OEMs. ARM also collaborated with third-party training companies and offered ARM design technology training programs to the employees of these OEMs. Secondly, ARM launched a university program to educate students with ARM IP and improve their IC design capabilities. We also encouraged university professors to write ARM IP-based programming and IC design books. But we did not pay for them, actually."

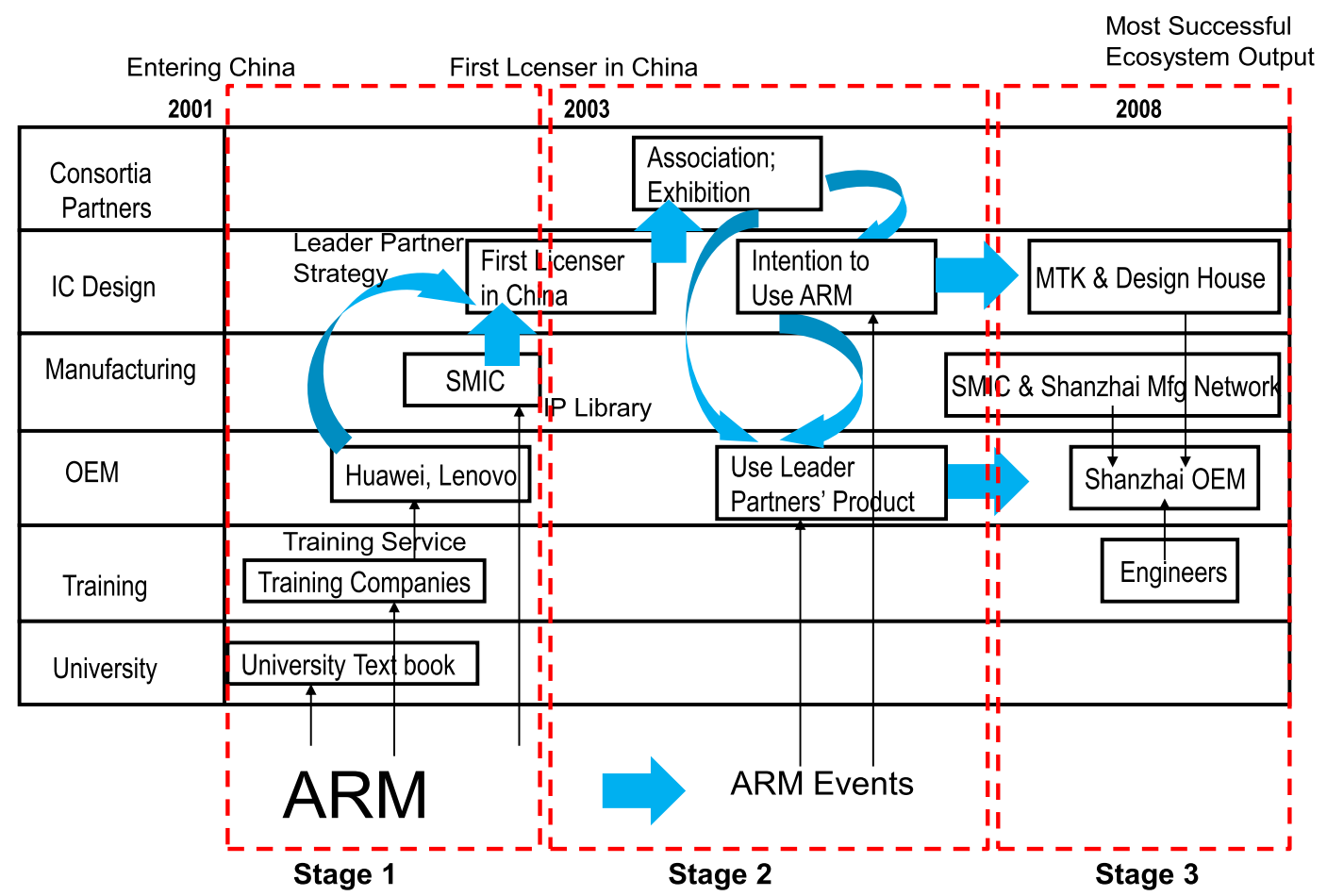

Fig. 2. ARM's activities to nurture its business ecosystem in China. 
These two strategies were intended to create a large base of engineers who understood ARM technology and were able to design microchips based on ARM IP. In addition, ARM China considered developing the manufacturing capacity of ARM microchips, aiming to shorten the product lead time and improve its quality. ARM licensed its physical IP to SMIC, a pure foundry company whose mission was to help ARM's partners optimize their microchip manufacturing capability and capacity.

\subsection{Stage 2: 2003-2008}

After gradually building up its engineering base and manufacturing feasibility in China, ARM started to license its IP to Chinese microchip design firms. The first licensee came in 2003 after two years of ARM efforts to build a friendly business environment for ARM IP commercialization, as shown in the second stage of nurturing (Fig. 2).

ARM regarded its licensees as leader partners. They worked closely with these leader partners. They selected them in two ways as they had already done in other markets. They selected the leading player in each market sector or they selected players that had strong expertise in a specific area for IP development. In China, most IC design firms were small, so ARM decided to identify small firms with strong potential.

After identifying the leader partners, four teams - the architecture team, marketing team, design team, and modeling team participated in this complex strategy. For the architecture and design teams, ARM received requirements from the leader partners and used them in new IP development. In order to keep up with the leader partners and reduce lead time, ARM's modeling team provided a simulation model of the new IP before its release; this helped leader partners develop their own products in advance. The marketing team also worked with leader partners to promote the new IP by highlighting ARM's strong business ecosystem support. The leader partner strategy was successfully used by ARM to promote several different types of IP in China, including ARM9, ARM11, and the Cortex M series. ARM's business ecosystem grew dramatically. ARM staff members agreed with the employee who said, "With the promotion and help of leader partners, ARM not only served as IP provider, but formed a large, close-knit community with top IC design companies to compete with other IP providers and potential competitors."

Following its leader partner strategy, the staff of ARM China took part in different industry exhibitions, consortia, and academic seminars to share their vision about the future of the market and the possibility of adopting ARM IP. For example, they organized an annual technology symposium, where they promoted their new technology, inviting guest speakers from successful leader partners and OEMs that used their leader partners' products. The SM product manager said, "As a leader partner for ARM, we have developed SMT32 based on Cortex-M series of ARM IP. We will together promote our next generation solutions in different automotive exhibitions." In addition, the CEO of ARM China gave talks at academic seminars of the Chinese embedding system association. ARM staff members also talked with the media and were always ready to take part in interviews.

\subsection{Stage 3: 2008 to present}

In 2008, the Shanzhai (Chinese white brand) mobile phone market was booming (Rong et al., 2011; Zhu and Shi, 2010), driven by an ARM leader partner, MTK. MTK is a chip design solution provider for consumer electronic products. MTK became famous in 2008 for nurturing China's booming local mobile phone market by integrating separate chips into one-chip turnkey solutions. More than half the Chinese local mobile phone market already used this turnkey solution.

An ARM China staff member said that without ARM's ecosystem, MTK could not have achieved such a resounding success. By 2008, ARM had already built up an ecosystem of partners who were able to design, manufacture, and promote ARM IP. For the Shanzhai manufacturing network in the south of China, MTK had to develop its innovation activity because it realized the importance of partnerships in its business ecosystem. MTK Shenzhen's marketing director said, "Thanks to ARM's ecosystem, we have found that there were many engineers and design houses that were familiar with ARM's technology. As a result, it was convenient to support many independent design houses (IDH), since they had experience with ARM IP and could deliver system design solutions based on MTK's turnkey model quickly." This system design allowed downstream players to develop new mobile phones easily. MTK also provided many training sessions on its technical specifications, which familiarized engineers with MTK's solutions, making it easy for the foundry companies to manufacture ARM IP-based MTK products.

As a result, MTK, being an ARM leader partner, worked closely with ARM to upgrade its solutions. At the same time, MTK boosted the Shanzhai manufacturing network, which was also influenced by ARM. This network provided $20 \%$ of all the world's mobile phone handset shipments in 2008 (Rong et al., 2011). This achievement demonstrates ARM's success, which is due to the nurtured ecosystem - the ecosystem partners merging their complementary capabilities and delivering quality products for ecosystem stakeholders.

The product manager of MTK commented on the strategy for stage 3 by saying, "As a leader partner, we also codevelop new IPs with ARM. In addition to the $2 \mathrm{G}$ mobile phone, we are also aiming at penetrating the mobile computing market, which requires advanced performance of ARM IP. We are also the part of ARM's ecosystem which promotes their IP in return and strengthens their business ecosystems."

In the course of these three stages, ARM had expanded its architecture to some degree and had offered relevant design tools to all its partners. Each partner was encouraged to contribute different ideas to ARM IP and to codevelop end user products. ARM had already identified its ecosystem partners as part of the connected community. The ARM connected community manager summarized the situation by noting, "With strong support from this connected community, ARM not only provides the IP itself, but also supports [it] with design tools, operating systems, and application softwares. These various connections further stimulate innovation opportunities." 


\section{Theory development}

\subsection{Ecosystem approach}

When the ecosystem matures, the core firm starts to optimize the ecosystem construct and categorize the different roles of its ecosystem partners (Lu et al., 2014). Generally speaking, direct business partners such as IC design firms are regarded as leader partners, who adopt ARM IP directly. The other ecosystem partners who contribute directly or indirectly to the ARM IP-based value chain, such as training companies, universities, and foundry companies, are regarded as complementary partners. By developing partnerships with these two major categories of partners, ARM started to build up the ecosystem in a brand new environment.

Previous studies on ARM's ecosystem (Garnsey et al., 2008; Williamson and De Meyer, 2012) or other typical business ecosystems mainly focused on innovative activities (Williamson and De Meyer, 2012; Kapoor and Lee, 2013; Rong et al., 2015) with potential ecosystem stakeholders, keystone players (Iansiti and Levien, 2004), and their platform strategies (Gawer and Cusumano, 2014) or on the structure of the business ecosystem (Adner and Kapoor, 2010). However, these theories neglected the business ecosystem in the context of international business (Best, 2014). In this paper, we have embedded the context of internationalization within business ecosystem nurturing.

An analysis of ARM's road map (with key stages and relevant stakeholders) as it entered the Chinese market reveals the steps involved in nurturing a business ecosystem in an unfamiliar environment. This research proposes a sequential triple-I nurturing model as shown in Fig. 3: incubating complementary partners, identifying leader partners, and integrating ecosystem partners.

\subsubsection{Incubating}

During the first stage, incubating complementary partners, companies such as ARM face unfamiliar environments, where there is not enough support from either partners or infrastructure; it is difficult to sell the product or license the technology. Hence, it is necessary to build a friendly, supportive environment for the new product or technology. ARM encouraged universities to develop textbooks on ARM technology; it provided potential OEM partners with training services concerning ARM technology. ARM also shared physical IP with foundry firms to guarantee manufacturing feasibility. As a result, the core company had successfully set up a supportive environment for its products to secure the potential market even before launching the business.

In sum, during the incubation stage, the core company works to incubate a supportive environment for marketing its products by sharing its vision with many non-direct business partners or complementary partners who are familiar with the core company's products.

\subsubsection{Identifying}

During the second stage, that of identifying leader partners, after securing a supportive environment for the product, the core company starts to identify the key customers with whom to work closely - not only on technology codevelopment, but also on comarketing. At this stage, the core company identifies leader partners either among the leading players in the industry or among small companies with strong business potential. The firm opens the door to its leader partners to codevelop future products. Additionally, the firm promotes these codeveloped products in many different consortia events, such as core company technology symposiums and industry exhibitions. They aim to persuade the end customers, such as OEMs, to adopt their products.

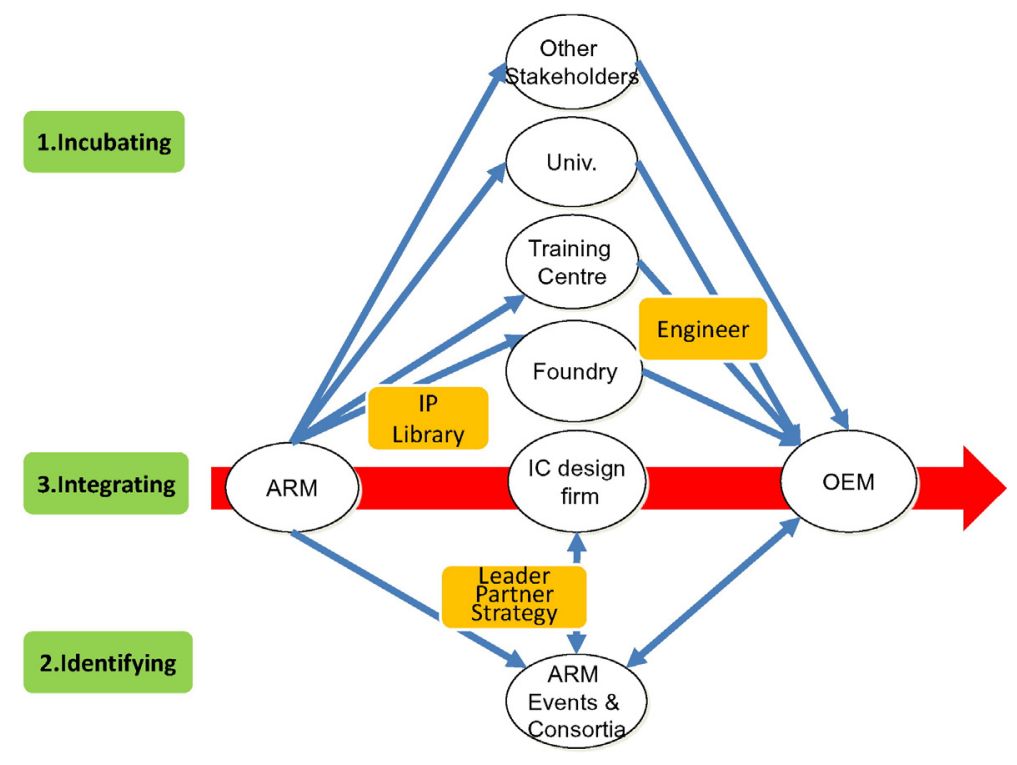

Fig. 3. The stages of nurturing business ecosystems. 
Table 2

Ecosystem approach to internationalization.

\begin{tabular}{|c|c|c|}
\hline & Nurturing process & Example \\
\hline \multirow[t]{2}{*}{ Incubating complementary partners } & Sharing vision and products & ARM IP shaping up to suit for future low-cost, low-power mobile phones \\
\hline & Incubating complementary partners & $\begin{array}{l}\text { Connecting with training companies; } \\
\text { convincing manufacturing firms; } \\
\text { encouraging universities }\end{array}$ \\
\hline Identifying leader partners & Identifying leader partners & Bringing IC design firms onboard as leader partners \\
\hline & Promoting the product and vision & Promoting products to potential downstream users at different events \\
\hline Integrating ecosystem partners & Categorizing ecosystem partners & $\begin{array}{l}\text { Classifying ecosystem partners in different categories with leader } \\
\text { partners and complementary partners }\end{array}$ \\
\hline & Stimulating self-integration & $\begin{array}{l}\text { Leader partners (e.g., MTK) organizing other ecosystem partners; } \\
\text { local OEMs becoming focal firms to coordinate local ecosystem partners }\end{array}$ \\
\hline
\end{tabular}

In sum, the identification stage aims to select the right leader partners with whom to eventually codevelop technology and copromote codeveloped products in the market.

\subsubsection{Integrating}

The third stage consists of integrating ecosystem partners. This stage demonstrates the capacity of a well-cultivated ecosystem to generate business. The ecosystem partners have been classified into different categories based on their expertise. At this stage, the key idea is to propose an appropriate product idea and encourage complementary ecosystem partners to work together. MTK is an appropriate case that demonstrated how ARM-coordinated ecosystem partners - such as local design houses, the core company, and local OEMs - could generate outstanding business results. The role of the core company, ARM, was to share its vision and motivate complementary partners. At this stage, the local OEMs became new focal firms who could coordinate and integrate the local partner network, especially the downstream network.

In general, the integration stage involves the clear classification of ecosystem partners and the stimulation of autonomous connections between complementary partners. The core company's role is to stimulate such connections.

The process of nurturing a business ecosystem is summarized in Table 2.

In sum, the ecosystem approach is different from classic internationalization theories, particularly as it focuses on both nurturing network resources and on transforming products. For example, if the industry already has finalized its products, focal firms can internationalize more gradually by expanding their network resources promoting the products. These theories are more concerned with the network and do not explore product status in depth. However, if posed with product uncertainty, focal firms should opt for more proactive strategies by nurturing their business ecosystems. Thus, focal firms not only nurture partner networks, but also foster their products and approach a dominant design. In this way, focal firms will stimulate the demand side. Alternatively, ecosystem partners might place the demand, making the focal firms attain it.

\subsection{Proposition development}

Based on the nurturing steps detailed in Table 2, this research also develops three propositions. Thus, we can further test why focal firms prefer to adopt the ecosystem approach when they are in context of internationalizing emerging industries with uncertain products. For our first proposition, as shown in Fig. 4, the technology platform owner, especially in an upstream position, is far from the end user products. They have to share their vision and persuade downstream partners to adopt their products. Sharing vision, identifying leader partners and connecting ecosystem partners are identified as key activities in the ecosystem approach. Hence, we develop the following proposition:

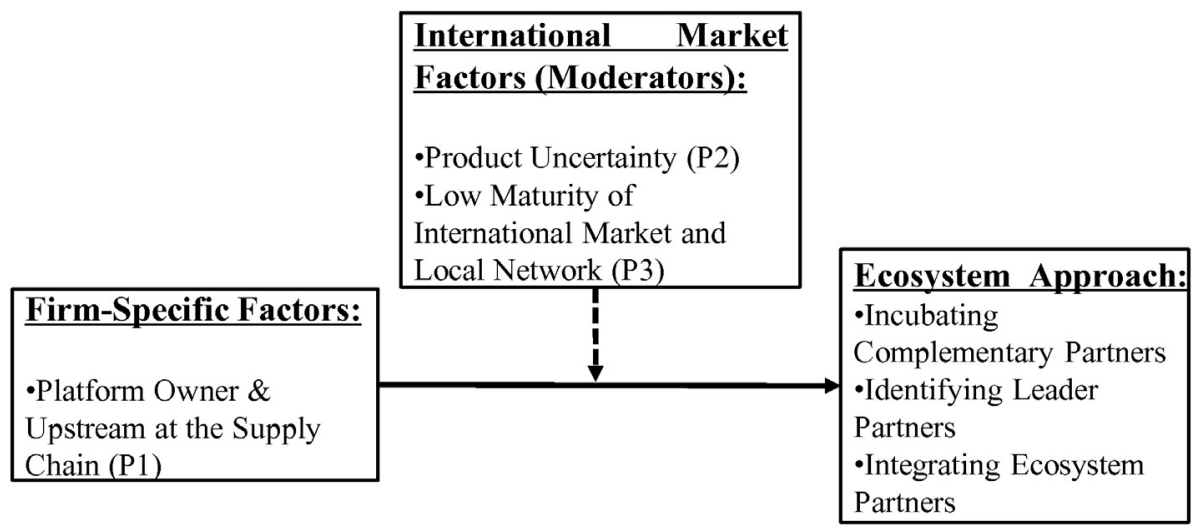

Fig. 4. Propositions developed from the ecosystem approach. 
Proposition 1. Technological platform providers prefer to take an ecosystem approach by, for example, sharing vision, connecting leader partners and integrating ecosystem partners, rather than by working directly with specific partners.

In some cases, the industrial end users products are not finalized. The technological platform provider also needs to encourage the downstream partner's effort and approach the dominant design with them. This strategy could enable the downstream partners to adopt the focal firms' product. Thus, we develop the second proposition:

Proposition 2. The positive relationship between technological platform provider and ecosystem approaches will be strengthened by product uncertainty.

To make matters worse, focal firms are entering new international markets that might lack the ability to support company networks and other resources. As a result, focal firms have to implement proactive strategies to create demand and incubate the supporting environment. They also need to take an ecosystem approach by identifying potential partners and sharing their vision with them. Thus, we develop our third proposition:

Proposition 3. The positive relationship between technological platform provider and ecosystem approaches will be strengthened by an immature international market and local network.

\section{Contribution to theories}

The fast-changing international business environment requires MNEs not only to address firm-level behavior, but also to manage global networks to meet the challenge of dynamic products (Dunning, 2001; Moghaddam et al., 2014). We summarize our contributions to the literature of international business and supply chain management in Table 3.

\subsection{Business ecosystem to enhance international business theories}

Our study provides a new angle and context of product uncertainty on the internationalization process, which is different from prior IB theories that focus on the OLI elements, mature products, and direct business partners. Our findings indicate that building a local stakeholder base and nurturing a business ecosystem should be the first step for internationalizing firms that operate in emerging industries with high product uncertainty.

In addition, our business ecosystem approach also enlarges the scope of classic IB theories and encourages focal firms to integrate indirect business partners besides the traditional direct partners. These partners assist focal firms not only in developing and promoting new products in local markets, but also in optimizing supply chains in a host country.

Finally, most classic IB theories do not address the dimension of international network configuration. Our three-stage business ecosystem-nurturing model is complementary to the stage model and the network approach, as it provides a theoretical framework to firms facing complex and uncertain international environments. Our case study suggests that proactively and sequentially identifying, incubating, and integrating stakeholders is an effective strategy to overcome the disadvantages in a foreign market.

\subsection{Enriching IPN, GSN, and demand chain management theories}

As shown in Table 3, our business ecosystem approach extends the context of operation-efficiency-oriented IPN and GSN theories from matured products to untraditional, complex environments with high product uncertainty. Hence, the firm should stimulate expansion of the scope of partners' innovation capabilities to initiate a dominant product design. The ecosystem approach encourages the different stakeholders by using an expanded partner network to trigger their collective activities.

In addition, this study identifies new internationalization patterns on how all stakeholders work together to facilitate the product commercialization of focal firms. This is different from both IPN and GSN theories that focus mostly on production-related partners.

Table 3

Comparison between internationalization theories.

\begin{tabular}{|c|c|c|c|}
\hline & Classic IB theories & IPN, GSN, and demand chain & Business ecosystem \\
\hline Context & $\begin{array}{l}\text { Lack of ownership, location, and } \\
\text { internalization advantages; search } \\
\text { for resources and assets }\end{array}$ & Need to reassess the network for a new market & $\begin{array}{l}\text { Enter foreign emerging markets with } \\
\text { untraditional challenges and complex } \\
\text { environments }\end{array}$ \\
\hline $\begin{array}{l}\text { Scope and } \\
\text { demand chain }\end{array}$ & $\begin{array}{l}\text { Direct partners; neglect the demand } \\
\text { chain }\end{array}$ & $\begin{array}{l}\text { Address the network by examining role types and their } \\
\text { evolution; address the demand chain, but mainly focus on } \\
\text { established market information }\end{array}$ & $\begin{array}{l}\text { Direct and indirect ecosystem partners; } \\
\text { explore and create future demand }\end{array}$ \\
\hline Pattern & $\begin{array}{l}\text { Relatively passive, gradual } \\
\text { expansion from firm perspective, } \\
\text { accumulated experience }\end{array}$ & $\begin{array}{l}\text { Expansion with network perspective by seeking new } \\
\text { markets; reassess network roles }\end{array}$ & $\begin{array}{l}\text { More proactive strategy, not only } \\
\text { encouraging network partners, but also } \\
\text { nurturing overseas ecosystem partners }\end{array}$ \\
\hline $\begin{array}{l}\text { Configuration of } \\
\text { network }\end{array}$ & Neglected & Generally stable Structure & Dynamic structure \\
\hline
\end{tabular}


Finally, our study provides new insights on configuration by proposing an ever-evolving structure as more and more partners become involved in a business ecosystem to cocreate value. This dynamic perspective is different from IPN, GSN, and demand management theories, which involves a stage in business ecosystem evolution when the product is finalized (Shang and Shi, 2013).

\subsection{Learning from demand perspective}

Our ecosystem approach provides theoretical implications on learning from the demand side during the internationalization process. First, if a firm operates in an emerging industry without established products and relevant internationalization support (such as skilled labor and business networks), then the firm had better create demand by sharing its vision with potential partners. It also has to incubate potential complementary partners to promote products. Second, focal firms also need to drive specific demands by working closely with leader partners, who, in turn, help focal firms identify and create specific demands. And finally, market demand will normally be developed in several streams along with industrial growth. For instance, in ARM's case, its original onesize-fits-all approach proved to be problematic in different international business contexts. ARM China had to divide its IP into three streams to adapt to new circumstances. In conclusion, the focal firm should work with leader partners and categorize their products to meet specific market demands. They need to embed a single market demand into their product design, thus enabling the ecosystem approach to successfully incorporate demand side information and product inspiration within the internationalization process, especially for those firms developing business in immature overseas markets without established products.

\section{Conclusion and future research}

\subsection{Extending business ecosystem theory}

This study provides a theoretical framework of the internationalizing business ecosystem and provides some insights to business ecosystem theories, in particular the business ecosystem life cycle concept (Moore, 1996), and applies it in a new international context. This research showcases the business ecosystem nurturing process composed of incubation, identification, and integration stages. This three-stage nurturing process improves our understanding of ecosystem development realized through the efforts of the focal firm. The ecosystem approach utilizes predominantly the proactive methods evolved from classic IB theories, such as, the stage model and the network approach. During the first stage, the ecosystem structure was not prevalent in China, as indicated in Adner and Kapoor's (2010) framework. Therefore, companies had to nurture the structure from scratch. There were no customers, complementors, or suppliers. As a result, companies had to incubate potential direct or indirect local partners. Next, in order to organize the ecosystem effectively, it was necessary to identify leader partners and cocreate value with them. At this stage, the focal firm and leader partners started to successfully tackle the problems concerning uncertain products and finally approached the dominant design. Ultimately, during the third stage, downstream partners such as OEMs were able to become focal firms. Thus, the focal firms benefitted from the efforts of leader partners and other stakeholders, adding more value to the products, scaling up the business, and simultaneously triggering downstream innovation activities. In sum, through the three sequential stages, the power of the business ecosystem gets unleashed, creating more value and enabling the focal firms and ecosystem partners to appropriate more value. This research explores post-entry and firm growth strategies on nurturing business ecosystems and provides new insights on the process view of internationalization. The findings are of a Mode 2 knowledge nature with respect to their application (Hessels and Van Lente, 2008; Jiménez, 2008) and offer a practical way of nurturing a business ecosystem.

This study also presents the key strategies in the framework of the three-stage process that is required for a focal firm to work with different players. For example, the focal firm should consider its leader partners as direct customers in the codevelopment and copromotion of products for downstream customers. The focal firm should also share its vision with complementors and co-evolve with them, enabling them to facilitate commercialization of products. The scope of the complementors includes not only the product, but also the human skill and financial levels. This scope needs to be expanded in order to support product commercialization fully.

Finally, this case study presents the importance of the process of self-organization or autonomy that is achieved after the focal firm's establishment of a business ecosystem. The focal firm will, above all, train the leader partners to enable them to integrate complementary partners into the ecosystem. Hence, not only will the focal firm integrate complementary partners, but it will also allow the leader partners to build up their own ecosystems. Such a process will make the ecosystem stronger and robust.

\subsection{Practical contribution}

This study provides industrial guidance to firms with cutting-edge technologies who wish to internationalize themselves into an emerging foreign market without network resources. The study proposes ways to nurture a business ecosystem, facilitating the internationalization process. It proposes an ecosystem strategy in three sequential stages to deal with product uncertainty: incubating local complementary partners, identifying leader partners, and integrating ecosystem partners. The first stage, incubating local complementary partners, might last a long time before companies make a profit. As a result, it is vital that planning activities (such as strategies to approach and motivate potential partners) and financial resources to support these activities are well organized. Such strategies will overcome cultural and institutional gaps and weak infrastructure support during the internationalization process.

With regard to its application context, we suggest that the model be applied in emerging industries with uncertain products in a context of international expansion. In such a context, the ecosystem approach as a proactive method could explore the demand side in-depth and encourage stakeholders to contribute to uncertain products. 


\subsection{Future research}

This research developed a three-stage framework explaining the process of nurturing business ecosystems to facilitate company growth in foreign markets in a context of no network resource advantages. Future research might generalize our research findings in four ways. First, the results of this study could be generalized, since it rigorously follows the rules of internal validity, construct validity, external validity, and liability (Gibbert et al., 2008); it uses data triangulation methods that incorporate the data from the focal firm, ARM, and its ecosystem partners and the secondary data. This paper has its own unique place, as it deals with a complex product that requires many partners for its development. Hence, this work will generally be applied to firms operating in emerging industries with complex products. However, this research could be further generalized using Platts' (1993) process approach and applying findings from several other sectors and conducting a broad survey. This process-based approach could then generalize our findings on applying the ecosystem approach and ensure its feasibility, usability, and utility (Platts, 1993). Second, researchers could further test this study's three propositions to confirm the contexts in which focal companies choose the ecosystem approach rather than the classic internationalization approach. Third, further studies should also examine the ecosystem itself, to improve understanding of the ecosystem structure, the building blocks of a business ecosystem, and the mechanisms used to organize these blocks. When the ecosystem structure is fully understood, there will be a need for a guide for industrial practitioners, suggesting ways for individual firms to nurture a business ecosystem. This guide would cover the components of business ecosystems in detail and outline the sequential steps needed to nurture such business ecosystems. Finally, a broader study is necessary to develop a framework of internationalization through business ecosystems and to identify how this differs from the creation of national ecosystems.

\section{Acknowledgment}

The authors thank ARM interviewees and their ecosystem partners for sharing their experience. This research is supported by the National Natural Science Foundation of China (Grant No. 71402051, No. 71003073) and by the BNP-KPMG endowed chair of business model and entrepreneurial innovation at NEOMA Business School. This research also benefitted from the support of the British Academy and the Society for the Advancement of Management Studies (SAMS) (Ref.:SG140243), and Bournemouth Study Leave Awards to Harvard Business School.

\section{Appendix A. ARM ecosystem interview list}

\begin{tabular}{|c|c|c|c|c|c|}
\hline Company name & Location & $\begin{array}{l}\text { Type of } \\
\text { business }\end{array}$ & Interviewee $(\mathrm{s})$ position & Ways & Duration \\
\hline ARM & $\begin{array}{l}\text { Cambridge, Shanghai, } \\
\text { Shenzhen, Beijing }\end{array}$ & IP provider & China CEO & $\begin{array}{l}\text { Interview, seminar, } \\
\text { phone call, e-mail }\end{array}$ & $13 \mathrm{~h}$ \\
\hline ARM & Beijing & IP provider & Mobile market manager & Interview, phone call, e-mail & $3 \mathrm{~h}$ \\
\hline ARM & Shenzhen, Shanghai & IP provider & Embedded market manager & Interview, phone call, e-mail & $8 \mathrm{~h}$ \\
\hline ARM & Shanghai & IP provider & Home market manager & Interview, phone call, e-mail & $4 \mathrm{~h}$ \\
\hline ARM & Cambridge & IP provider & ARM7/9 project manager & Interview, e-mail follow-up & $2 \mathrm{~h}$ \\
\hline ARM & Cambridge & IP provider & Product manager & Interview, e-mail follow-up & $1 \mathrm{~h}$ \\
\hline ARM & Cambridge & IP provider & CPU project manager & Interview & $0.5 \mathrm{~h}$ \\
\hline ARM & Cambridge & IP provider & Connected community manager & Interview, phone call, e-mail & $8 \mathrm{~h}$ \\
\hline ARM & Cambridge & IP provider & software engineering & Interview, phone call, e-mail & $8 \mathrm{~h}$ \\
\hline \multicolumn{6}{|c|}{ ARM's ecosystem partners } \\
\hline MTK & Taiwan & IC design & Product manager & $\begin{array}{l}\text { Interview, seminar, } \\
\text { phone call, e-mail }\end{array}$ & $8 \mathrm{~h}$ \\
\hline MTK & Beijing & IC design & Marketing director & Interview, phone call, e-mail & $8 \mathrm{~h}$ \\
\hline MTK & Taiwan & IC design & Marketing manager & Interview, phone call, e-mail & $4 \mathrm{~h}$ \\
\hline Synopsys & Silicon Valley & EDA & Group manager, foundry program & Interview & $2 \mathrm{~h}$ \\
\hline ST & Beijing & IC design & Business development manager & Interview & $1 \mathrm{~h}$ \\
\hline ST & Shanghai & IC design & Marketing section manager, MCU & Interview & $1 \mathrm{~h}$ \\
\hline ST & Shenzhen & IC design & Application manager, MCU & Interview & $0.5 \mathrm{~h}$ \\
\hline Hisilicon & Shenzhen & IC design & Marketing manager & Interview & $1 \mathrm{~h}$ \\
\hline Spreadtrum & Beijing & IC design & Marketing director & Interview & $2 \mathrm{~h}$ \\
\hline Datang & Shanghai & IC design & Hardware engineer & Interview & $1 \mathrm{~h}$ \\
\hline Symbian Foundation & London & OSV & Catalyst and futurist, leadership team & Interview, e-mail & $2 \mathrm{~h}$ \\
\hline Symbian Foundation & London & OSV & Research community manager & Interview, phone call, e-mail & $2 \mathrm{~h}$ \\
\hline Montavista & Cambridge & OSV & Account sales manager & Interview & $1 \mathrm{~h}$ \\
\hline Google & Silicon Valley & OSV & Product manager & Interview & $1 \mathrm{~h}$ \\
\hline Google & Silicon Valley & OSV & Enterprise mid-market senior sales manager & Interview & $1 \mathrm{~h}$ \\
\hline Microsoft & Seattle & OSV & Outsourcing director, Microsoft Game Studios & Interview & $1 \mathrm{~h}$ \\
\hline Tecent & Shenzhen & ISV & Executive secretary general of Tecent PWCF & Interview, e-mail & $2 \mathrm{~h}$ \\
\hline
\end{tabular}


Appendix A (continued)

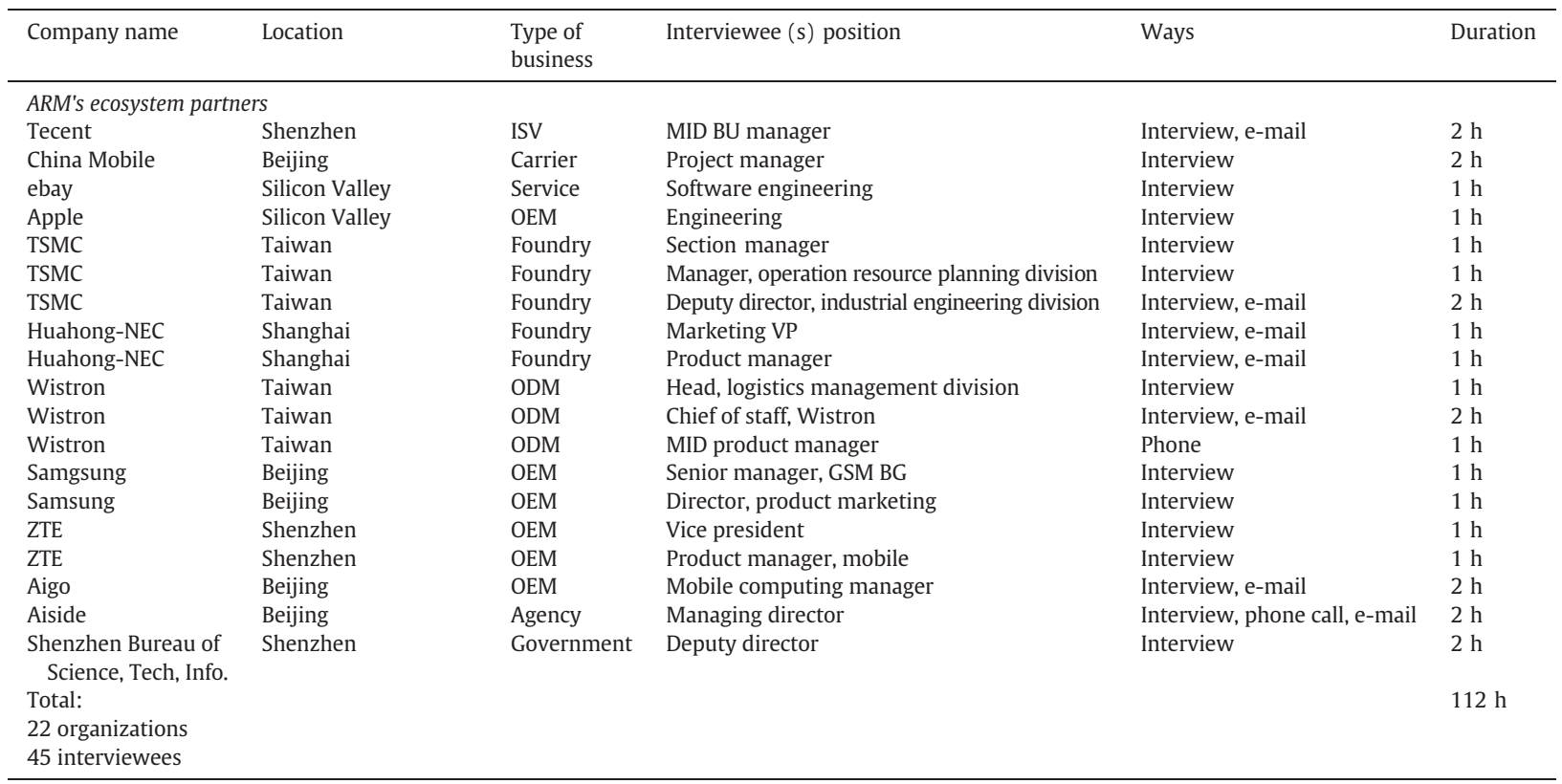

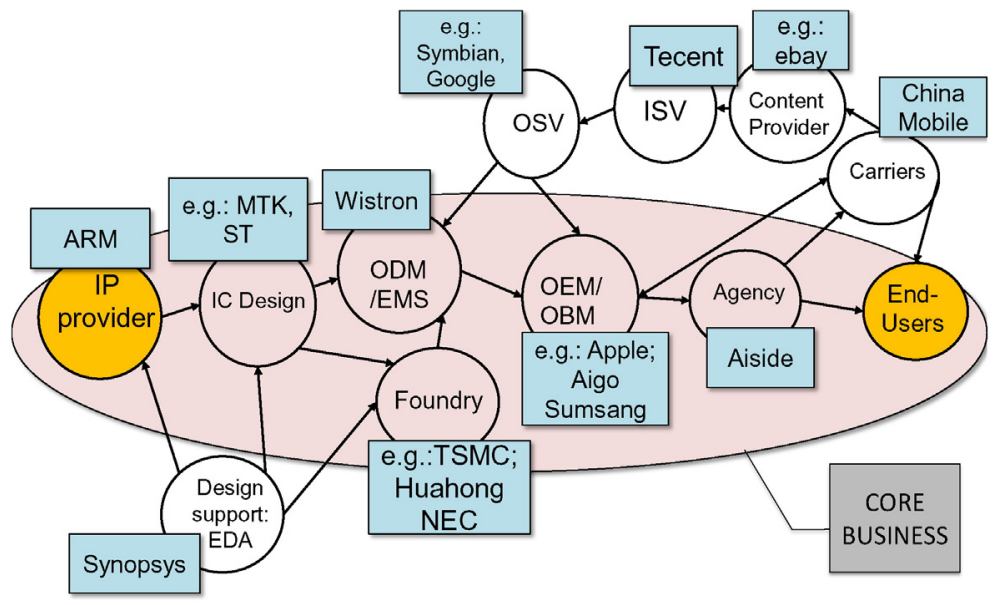

IP- Intellectual Property, IC- Integrated Circuit, OEM- Original Equipment Manufacturer, OSV- Operating System Vendor, EDA- Electronic Design Assistant ISV- Independent System Vendor, EMS: Electronics Manufacturing Service; ODM- Original Design Manufacturer.

Appendix Fig. 1. Companies interviewed in ARM's ecosystem.

\section{References}

Adner, R., 2012. The Wide Lens: A New Strategy for Innovation. Portfolio/Penguin, New York.

Adner, R., Kapoor, R., 2010. Value creation in innovation ecosystems: how the structure of technological interdependence affects firm performance in new technology generations. Strateg. Manag. J. 31, 306.

Andersson, U., Björkman, I., Forsgren, M., 2005. Managing subsidiary knowledge creation: the effect of control mechanisms on subsidiary local embeddedness. Int. Bus. Rev. 14, 521.

ARM Holdings, PLC, 2014. Annual report (http://ir.arm.com/phoenix.zhtml?c=197211\&p=irol-reportsannual (Accessed 3/16/15)).

Bandura, A., 2001. Social cognitive theory: an agentic perspective. Annu. Rev. Psychol. 52, 1.

Behrens, A., 2012. The international business academic and business ecosystem is misaligned, but alignment may miss the larger research goals. Thunderbird Int. Bus. Rev. 54, 239.

Bell, J., 1995. The internationalization of small computer software firms: a further challenge to 'stage' theories. Eur. J. Mark. $29,60$.

Best, M.H., 2014. Greater Boston's industrial ecosystem: a manufactory of sectors. Technovation. http://dx.doi.org/10.1016/j.technovation.2014.04.004. 
Blomstermo, A., Eriksson, K., Lindstrand, A., Sharma, D.D., 2004. The perceived usefulness of network experiential knowledge in the internationalizing firm. J. Int. Manag. 10, 355.

Buckley, P.J., Casson, M., 1976. The Future of the Multinational Enterprise. Macmillan, London.

Burt, R.S., 2010. Neighbor Networks: Competitive Advantage Local and Personal. Oxford University Press, New York.

Burt, J., 2014. ARM server chips forcing Intel to defend market it's long dominated. p. 2 (eWeek, 30 June).

Chen, T.-.., 2003. Network resources for internationalization: the case of Taiwan's electronics firms*. J. Manag. Stud. 40, 1107.

Chen, H., Chen, T.-J., 1998. Network linkages and location choice in foreign direct investment. J. Int. Bus. Stud. 29, 445.

Chen, T.-J., Chen, H., Ku, Y.-H., 2004. Foreign direct investment and local linkages. J. Int. Bus. Stud. 35, 320.

Chesbrough, H., Sohyeong, K., Agogino, A., 2014. Chez Panisse: building an open innovation ecosystem. Calif. Manag. Rev. 56, 144.

Chetty, S., Blankenburg Holm, D., 2000. Internationalisation of small to medium-sized manufacturing firms: a network approach. Int. Bus. Rev. 9, 77.

Child, J., Rodrigues, S.B., 2005. The internationalization of Chinese firms: a case for theoretical extension? Manag. Organ. Rev. 1, 381.

Christopher, M., 2010. Logistics and Supply Chain Management. Financial Times/Prentice Hall, London.

Ciravegna, L., Majano, S.B., Zhan, G., 2014. The inception of internationalization of small and medium enterprises: the role of activeness and networks. J. Bus. Res. 67, 1081.

Collinson, S.C., Wang, R., 2012. The evolution of innovation capability in multinational enterprise subsidiaries: dual network embeddedness and the divergence of subsidiary specialisation in Taiwan. Res. Policy 41, 1501.

Contractor, F.J., 2007. Is international business good for companies? The evolutionary or multi-stage theory of internationalization vs. the transaction cost perspective. Manag. Int. Rev. 47, 453.

Cusumano, M.A., 2011. The platform leader's dilemma. Commun. ACM 54, 21.

De Treville, S., Shapiro, R.D., Hameri, A.-P., 2004. From supply chain to demand chain: the role of lead time reduction in improving demand chain performance. J. Oper. Manag. 21, 613.

Dellestrand, H., 2011. Subsidiary embeddedness as a determinant of divisional headquarters involvement in innovation transfer processes. J. Int. Manag. 17, 229.

Denk, N., Kaufmann, L., Roesch, J.-F., 2012. Liabilities of foreignness revisited: a review of contemporary studies and recommendations for future research. J. Int. Manag. $18,322$.

Doz, Y., Santos, J., Williamson, P., 2004. Is your innovation process global? MIT Sloan Manag. Rev. 45, 31.

Dunning, J., 1988. The eclectic paradigm of international production: a restatement and some possible extensions. J. Int. Bus. Stud. 19, 1.

Dunning, J.H., 2000. The eclectic paradigm as an envelope for economic and business theories of MNE activity. Int. Bus. Rev. 9, 163.

Dunning, J.H., 2001. The eclectic (OLI) paradigm of international production: past, present and future. Int. J. Econ. Bus. 8, 173.

Dunning, J.H., Lundan, S.M., 2008. Institutions and the OLI paradigm of the multinational enterprise. Asia Pac. J. Manag. $25,573$.

Eisenhardt, K.M., 1989. Building theories from case study research. Acad. Manag. Rev. 14, 532.

Eisingerich, A.B., Bell, S.J., Tracey, P., 2010. How can clusters sustain performance? The role of network strength, network openness, and environmental uncertainty. Res. Policy 39, 239.

Ferdows, K., 1997. Making the most of foreign factories. Harv. Bus. Rev. 75, 73.

Fisch, J.H., Zschoche, M., 2012. The role of operational flexibility in the expansion of international production networks. Strateg. Manag. J. $33,1540$.

Garnsey, E., Lorenzoni, G., Ferriani, S., 2008. Speciation through entrepreneurial spin-off: the Acorn-ARM story. Res. Policy 37, 210.

Gawer, A., Cusumano, M.A., 2014. Industry platforms and ecosystem innovation. J. Prod. Innov. Manag. 31, 417.

Ge, G., Wang, H., 2013. The impact of network relationships on internationalization process: an empirical study of Chinese private enterprises. Asia Pac. J. Manag. 30, 1169.

Geringer, J.M., 1991. Strategic determinants of partner selection criteria in international joint ventures. J. Int. Bus. Stud. $22,41$.

Ghoshal, S., Bartlett, C.A., 1990. The multinational corporation as an interorganizational network. Acad. Manag. Rev. 15, 603.

Gibbert, M., Ruigrok, W., Wicki, B., 2008. What passes as a rigorous case study? Strateg. Manag. J. 29, 1465.

Gibbons, M., Limoges, C., Nowotny, H., Schartzman, S., Scott, P., Trow, M., 1997. The New Production of Knowledge: The Dynamics of Science and Research in Contemporary Societies. Sage Publications, London.

Gooris, J., Peeters, C., 2014. Home-host country distance in offshore governance choices. J. Int. Manag. $20,73$.

Gulati, R., Puranam, P., Tushman, M., 2012. Meta-organization design: rethinking design in interorganizational and community contexts. Strateg. Manag. J. $33,571$.

Hessels, L.K., Van Lente, H., 2008. Re-thinking new knowledge production: a literature review and a research agenda. Res. Policy 37, 740.

Hilletofth, P., 2011. Demand-supply chain management: industrial survival recipe for new decade. Ind. Manag. Data Syst. 111, 184.

Hilmersson, M., Jansson, H., 2012. International network extension processes to institutionally different markets: entry nodes and processes of exporting SMEs. Int. Bus. Rev. 21, 682.

Hymer, S., 1976. The International Operations of National Firms: A Study of Direct Foreign Investment. MIT Press, Cambridge.

Iansiti, M., Levien, R., 2004. The Keystone Advantage: What the New Dynamics of Business Ecosystems Mean for Strategy, Innovation, and Sustainability. Harvard Business School Press, Boston.

Immelt, J.R., Govindarajan, V., Trimble, C., 2009. How GE is disrupting itself. Harv. Bus. Rev. 87, 56.

Ji, J., Dimitratos, P., 2013. Confucian dynamism and Dunning's framework: direct and moderation associations in internationalized Chinese private firms. J. Bus. Res. 66, 2375.

Jiménez, J., 2008. Research socially responsible: may we speak of a mode 3 knowledge production. RECIIS Electron. J. Commun. Inf. Innov. Health 2, 48.

Johanson, J., Mattsson, L.G., 1988. Internationalization in industrial systems - a network approach. In: Buckley, P.J., Ghauri, P.N. (Eds.), The Internationalization of the Firm: A Reader. Academic Press, London, p. 303.

Johanson, J., Vahlne, J.-E., 1977. The internationalization process of the firm - a model of knowledge development and increasing foreign market commitments. J. Int. Bus. Stud. 8, 23.

Johanson, J., Vahlne, J.-E., 2009. The Uppsala internationalization process model revisited: from liability of foreignness to liability of outsidership. J. Int. Bus. Stud. 40, 1411.

Johanson, J., Wiedersheim-Paul, F., 1975. The internationalization of the firm - four Swedish cases. J. Manag. Stud. 12, 305.

Jüttner, U., Christopher, M., Baker, S., 2007. Demand chain management - integrating marketing and supply chain management. Ind. Mark. Manag. $36,377$.

Kaeslin, H., 2014. Top-Down Digital VLSI Design: From Architectures to Gate-Level Circuits and FPGAs. Morgan Kaufmann, Waltham, MA.

Kapoor, R., Lee, J.M., 2013. Coordinating and competing in ecosystems: how organizational forms shape new technology investments. Strateg. Manag. J. 34, 274.

Keeble, D., Lawson, C., Smith, H.L., Moore, B., Wilkinson, F., 1998. Internationalisation processes, networking and local embeddedness in technology-intensive small firms. Small Bus. Econ. 11, 327.

Kenney, M., Pon, B., 2011. Structuring the smartphone industry: is the mobile internet OS platform the key? J. Ind. Compet. Trade 11, 1.

Korhonen, P., Huttunen, K., Eloranta, E., 1998. Demand chain management in a global enterprise-information management view. Prod. Plan. Control 9, 526.

Lambert, D.M., Cooper, M.C., 2000. Issues in supply chain management. Ind. Mark. Manag. $29,65$.

Lee, J.W., Song, H.S., Kwak, J., 2014. Internationalization of Korean banks during crises: the network view of learning and commitment. Int. Bus. Rev. $23,1040$.

Li, X., Shi, Y., Gregory, M., 2000. Global Manufacturing Virtual Network (GMVN) and its position in the spectrum of strategic alliance. Operations Management: Crossing Borders and Boundaries: The Changing Role of Operations, EurOMA 7th International Annual Conference, Ghent, Belgium, p. 330.

Liu, S., Moizer, J., Megicks, P., Kasturiratne, D., Jayawickrama, U., 2014. A knowledge chain management framework to support integrated decisions in global supply chains. Prod. Plan. Control 25, 639

Lu, C., Rong, K., You, J., Shi, Y., 2014. Business ecosystem and stakeholders' role transformation: evidence from Chinese emerging electric vehicle industry. Expert Syst. Appl. 41, 4579.

Mäkinen, S.J., Kanniainen, J., Peltola, I., 2014. Investigating adoption of free beta applications in a platform-based business ecosystem. J. Prod. Innov. Manag. 31, 451. Mills, J., Platts, K., Gregory, M., 1995. A framework for the design of manufacturing strategy processes. Int. J. Oper. Prod. Manag. 15, 17. 
Moeller, M., Harvey, M., 2011. Inpatriate marketing managers: issues associated with staffing global marketing positions. J. Int. Mark. $19,1$.

Moghaddam, K., Sethi, D., Weber, T., Wu, J., 2014. The smirk of emerging market firms: a modification of the Dunning's typology of internationalization motivations. J. Int. Manag. 20, 359,

Moore, J., 1993. Predators and prey: a new ecology of competition. Harv. Bus. Rev. 71, 75.

Moore, J.F., 1996. The Death of Competition: Leadership \& Strategy in the Age of Business Ecosystems. HarperBusiness, New York.

Musteen, M., Datta, D.K., Butts, M.M., 2014. Do international networks and foreign market knowledge facilitate SME internationalization? Evidence from the Czech Republic. Entrep. Theory Pract. 38, 749.

Neely, A., Mills, J., Platts, K., Richards, H., Gregory, M., Bourne, M., Kennerley, M., 2000. Performance measurement system design: developing and testing a processbased approach. Int. J. Oper. Prod. Manag. 20, 1119.

Nell, P.C., Ambos, B., 2013. Parenting advantage in the MNC: an embeddedness perspective on the value added by headquarters. Strateg. Manag. J. $34,1086$.

Newburry, W., Yakova, N., 2006. Standardization preferences: a function of national culture, work interdependence and local embeddedness. J. Int. Bus. Stud. 37, 44.

Nowotny, H., Scott, P., Gibbons, M., 2003. Introduction: mode 2 revisited: the new production of knowledge. Minerva 41, 179.

Pananond, P., 2013. Where do we go from here? Globalizing subsidiaries moving up the value chain. J. Int. Manag. 19, 207.

Parente, R.C., Baack, D.W., Hahn, E.D., 2011. The effect of supply chain integration, modular production, and cultural distance on new product development: a dynamic capabilities approach. J. Int. Manag. 17, 278.

Phaal, R., Muller, G., 2009. An architectural framework for roadmapping: towards visual strategy. Technol. Forecast. Soc. Chang. 76, 39.

Phaal, R., Farrukh, C.J., Probert, D.R., 2004. Technology roadmapping - a planning framework for evolution and revolution. Technol. Forecast. Soc. Chang. 71, 5.

Phaal, R., O'Sullivan, E., Routley, M., Ford, S., Probert, D., 2011. A framework for mapping industrial emergence. Technol. Forecast. Soc. Chang. 78, 217.

Platts, K.W., 1993. A process approach to researching manufacturing strategy. Int. J. Oper. Prod. Manag. 13, 4.

Priem, R.L., Swink, M., 2014. A demand-side perspective on supply chain management. J. Supply Chain Manag. 48, 7.

Priem, R.L., Li, S., Carr, J.C., 2012. Insights and new directions from demand-side approaches to technology innovation, entrepreneurship, and strategic management research. J. Manag. 38, 346.

Rainbird, M., 2004. Demand and supply chains: the value catalyst. Int. J. Phys. Distrib. Logist. Manag. 34, 230.

Reid, S.E., De Brentani, U., 2010. Market vision and market visioning competence: impact on early performance for radically new, high-tech products. J. Prod. Innov. Manag. 27, 500.

Rong, K., Liu, Z., Shi, Y., 2011. Reshaping the business ecosystem in China: case studies and implications. J. Sci. Technol. Policy China 2, 171.

Rong, K., Hu, G., Hou, J., Ma, R., Shi, Y., 2013a. Business ecosystem extension: facilitating the technology substitution. Int. J. Technol. Manag. 63, 268.

Rong, K., Lin, Y., Shi, Y., Yu, J., 2013b. Linking business ecosystem lifecycle with platform strategy: a triple view of technology, application and organization. Int. J. Technol. Manag. 62, 75 .

Rong, K., Shi, Y., Yu, J., 2013c. Nurturing business ecosystem to deal with industry uncertainties. Ind. Manag. Data Syst. 133, 385.

Rong, K., Hu, G., Lin, Y., Shi, Y., Guo, L., 2015. Understanding business ecosystem using a 6C framework in internet-of-things-based sectors. Int. J. Prod. Econ. $159,41$.

Saunders, M., Lewis, P., Thornhill, A., 2009. Research Methods For Business Students. fifth ed. Pearson Education Ltd., Essex, UK.

Schmeisser, B., 2013. A systematic review of literature on offshoring of value chain activities. J. Int. Manag. 19, 390.

Schweizer, R., 2013. SMEs and networks: overcoming the liability of outsidership. J. Int. Entrep. 11, 80.

Secchi, D., 2009. The cognitive side of social responsibility. J. Bus. Ethics 88, 565.

Shang, T., Shi, Y., 2013. The emergence of the electric vehicle industry in Chinese Shandong Province: a research design for understanding business ecosystem capabilities. J. Chin. Entrep. 5, 61.

Shi, Y., Gregory, M., 1998. International manufacturing networks - to develop global competitive capabilities. J. Oper. Manag. 16, 195

Shi, Y., Gregory, M., 2005. Emergence of global manufacturing virtual networks and establishment of new manufacturing infrastructure for faster innovation and firm growth. Prod. Plan. Control 16, 621.

Srai, J.S., Gregory, M., 2008. A supply network configuration perspective on international supply chain development. Int. J. Oper. Prod. Manag. 28, 386.

Thomas, L.D., Autio, E., Gann, D.M., 2015. Architectural leverage: putting platforms in context. Acad. Manag. Perspect. 3015, 47.

Uzzi, B., 1996. The sources and consequences of embeddedness for the economic performance of organizations: the network effect. Am. Sociol. Rev. 61, 674.

Vahlne, J.-E., Schweizer, R., Johanson, J., 2012. Overcoming the liability of outsidership - the challenge of HQ of the global firm. J. Int. Manag. 18, 224.

Validi, S., Bhattacharya, A., Byrne, P.J., 2014. Integrated low-carbon distribution system for the demand side of a product distribution supply chain: a DoE-guided MOPSO optimiser-based solution approach. Int. J. Prod. Res. 52, 3074

Van Aken, J.E., 2005. Management research as a design science: articulating the research products of mode 2 knowledge production in management. Br.J. Manag. $16,19$.

van Veen-Dirks, P.M.G., Verdaasdonk, P.J.A., 2009. The dynamic relation between management control and governance structure in a supply chain context. Supply Chain Manag. Int. J. 14, 466

Vernon, R., 1966. International investment and international trade in the product cycle. Q. J. Econ. 80, 190.

Wang, J., Wei, Y., Liu, X., Wang, C., Lin, H., 2014. Simultaneous impact of the presence of foreign MNEs on indigenous firms' exports and domestic sales. Manag. Int. Rev. $54,195$.

Wareham, J., Fox, P.B., Cano Giner, J.L., 2014. Technology ecosystem governance. Organ. Sci. 25, 1195.

Welch, C., Paavilainen-Mäntymäki, E. 2014. Putting process (back) in: research on the internationalization process of the firm. Int. J. Manag. Rev. 16, 2.

Williams, T., Maull, R., Ellis, B., 2002. Demand chain management theory: constraints and development from global aerospace supply webs. J. Oper. Manag. $20,691$.

Williamson, P.J., De Meyer, A., 2012. Ecosystem advantage: how to successfully harness the power of partners. Calif. Manag. Rev. 55, 24.

Yang, J., Tipton, F., Li, J., 2011. A review of foreign business management in China. Asia Pac. J. Manag. 28, 627.

Yin, R.K., 2008. Case Study Research: Design and Methods. fourth ed. Sage Publications, Thousand Oaks, CA.

Zaheer, S., 1995. Overcoming the liability of foreignness. Acad. Manag. J. 38, 341.

Zhang, Y., Gregory, M., 2011. Managing global network operations along the engineering value chain. Int. J. Oper. Prod. Manag. 31, 736.

Zhu, S., Shi, Y., 2010. Shanzhai manufacturing - an alternative innovation phenomenon in China: its value chain and implications for Chinese science and technology policies. J. Sci. Technol. Policy China 1, 29. 